\title{
How Do We Transform our Large-Group Identities?
}

\author{
Peter T. Dunlap, Ph.D.*
}

\begin{abstract}
While Jung was particularly critical of groups, he also had a vision of humans as a selfaware, problem-solving being. In this paper I explore his interest in and critique of, or prejudice against, groups. I raise the issue of whether it is possible to transform consciously our large-group identities, thus making them more morally responsive to the conditions they find themselves in. I focus specifically on recent social science research regarding the psychocultural function of emotion and group theory and practice that could be used by a new generation of "psychocultural practitioners" to develop the theory and practices of large-group transformation that would aid in the moral development of a group's conscience. I also propose that the Jungian communities could participate in the founding of such a distinctive vocation, which would formalize numerous informal and innovative practices that many are already engaged in.
\end{abstract}

Through an exploration of Jung's foundational thought it is possible to step outside of his prejudices against groups, which were shared by many cultural leaders of his time, and foster a new perspective (Coleman, 1995, p. 19; Dunlap, 2016, pp. 93-94). It is my hope that the results of such inquiry will support a more integrated praxis that the Jungian community will be able to use within its organizations and in multiple other settings. Psychotherapists can learn to move out of the clinic and their private practices, and educators can learn to move out of the classroom for purposes of establishing political practice. I see such work emerging through a wide variety of distinct disciplines that may benefit from some effort to consolidate them into a new vocational form led by a new generation of "psychocultural practitioners" who apply Jung's vision of the unity of human experience in order to bring the moral implications of that vision to the work of transforming large-group identities. A psychocultural practitioner would take responsibility for bringing a "psychological attitude" to issues of group development and to the critical social and political questions of our time (Henderson, 1984). Practitioners of this vocation are learning how to apply some conscious pressure on our group identities.

*centerpd@gmail.com 
In this paper I will briefly review a bit of Jung's thinking about the "developmental" interplay between the individual and collective, specifically the way in which individuals can become the moral leaders of their time as they confront their own and their community's shadow dynamics; I will offer a cursory summary of recent research regarding the psychocultural functions of affect, emotion, and feeling and their implications for a theory of "psychocultural development" based, in part, on Jung; and I will link these to other recent research regarding group development. ${ }^{1}$

While no one stepping stone along the trail of this thesis will be covered in depth and several steps may require a leap of faith, the importance of changing large-group identities warrants speculation. As Jung (1959) notes, it is large-groups that sweep individuals into the mass-mindedness that leads to the worst horrors of our time; therefore, by learning more about how these identities form and how they can be consciously changed, we can learn more about the moral development of groups (p. 9; cf. 1946a pp. 218-226).

\section{Jung's unitive vision of psyche and his prejudice against groups}

Much of Jung's work consisted of his efforts to find a way to develop a psychological attitude that could mend dissociations between psyche and instinct. According to Shamdasani (2003), Jung thought that the institution of psychology could coordinate this project and, in fact, be its foundation (p. 15). By using the psychological attitude, he hoped to account for the differences in focus and interest among social scientists and among the different scientific disciplines for the sake of developing a more synchronized response to the troubles of modern culture and the ills of the modern psyche (pp. 318-320). This hope for a united human effort was fueled by Jung's vision of humanity as a single form of life, a united self-aware being. He wrote,

If it were possible to personify the unconscious, we might think of it as a collective human being combining the characteristics of both sexes, transcending youth and age, birth and death, and, from having at its command a human experience of one or two million years, practically immortal. If such a being existed, it would be exalted above all temporal change; the present would mean neither more nor less to it than any year in the hundredth millennium before Christ; it would be a dreamer of age-old dreams and, owing to its limitless experience, an incomparable prognosticator. It would have lived countless times over again the life of the individual, the family, the tribe, and the nation, and it would possess a living sense of the rhythm of growth, flowering, and decay. (1931, pp. 349-350). 
Jung's goal of looking for such a being was not merely to try to describe the indescribable collective unconscious. Rather, it was to entertain the radical potential of the idea that the collective unconscious could become conscious. For example, in 1939, eight years after writing the above fantastical description of the personified collective unconscious, Jung returns to similar territory by considering whether the disassociated fragments he found in dream imagery could be generated by a superior personality that was providing direction for consciousness, a personality not yet fully developed and therefore "dormant or dreaming" (p. 283). Again, a few years later in 1946, Jung takes up a related question by wondering if the unconscious has its own ego-center, a "superconsciousness" the implications of which "[are] of absolutely revolutionary significance in that it could radically alter our view of the world" (1946b, pp. 177-178). While there are many ways of interpreting Jung's few words on the subject, there is little doubt that his own encounter with the unconscious motivated these incredible speculations.

As he documented in The red book (2009), Jung cultivated handholds between his modern, isolated individual identity and something greater, a unique, individuated connection to humanity as a whole. This quest required that he pass through layers of the unconscious, by which he meant those parts of his individual and collective humanity from which he had been cut off. Such encounters with the unconscious included confronting painful experiences through dream imagery, fantasy, and repressed emotions, often awakening exalted emotions associated with the "religious experiences" written about by many including Jung (1936) and James (1902), (cf. Fosha, 2000, p. 18). ${ }^{2}$

Also like James, Jung (1958) attended to these experiences through careful examination and came to speak of this transformative capacity of the human psyche as the "transcendent function," by which human beings could reconnect to the positive value of instinct and direct their attention to the personal meaning of these occurrences as well as to their collective implications as the "moral demands" of such experiences (p. 68, 82). These encounters with the unconscious evoked what Jung (1946a) thought of as archetypal symbols, a term that functions in his work to identify the universal capacity of human beings to develop and transform their own consciousness while learning to address the crises of their time, thus becoming the moral leaders of humankind (p. 221). However, he did not idealize archetypal experience, for he also recognized its destructive potency.

Jung (1946) recognized that, when modern culture became unmoored from instinct, archetypal energies were released into individual and collective experience with horrifying consequences (1946a, p. 219). Under such conditions, intensified affect becomes contagious and is too easily manipulated through evocative imagery that 
disturbs large-group identifications, turning groups against one another or toward the scapegoating of other vulnerable groups (Singer, 2004, p. 20). Jung speaks of these dynamics as the release of the power drive of the "shadow" by which he meant a "lower" part of the individual's personality that gets projected outward onto others who interfere with that person's ability to know what is real. Jung (1946a) also identified the way in which whole peoples can project their shadows onto other groups, thus demonizing and waging war on them, rather than undertaking the truly difficult psychological work of facing one's shadow and integrating its painful experience (pp. 223-225).

Jung's (1946a) response to this destructive psychocultural reality was to assert that collective shadow phenomena, both imaginal and emotional, could only be integrated into consciousness through the esoteric work of an individual consciousness: One must humbly attend to one's own inferiority by acknowledging emotions that would otherwise seize control and by integrating those emotions into consciousness rather than projecting them onto demonized others. By confronting his own inferiority Jung (1946a) worked to integrate his shadow, a process he later articulated as the theory and practice of individuation (p. 221).

Following his experience of confronting his own shadow, Jung researched the esoteric nature of the religious experience of gifted individuals, particularly the way such an experience activated a "religious attitude" capable of transforming their personal identity, to give it a new shape, one that would be responsive to the moral issues of their cultural context (Henderson, 1984, p. 27). Jung (1919) described the way such individuals have the potential to become cultural leaders as they encounter what has been neglected or denied by their culture as it lives in their own life experience, that is, as the individuals face the emotional repressions, prejudices, and sociopolitical failures of their time (p. 314; cf. 1946a, p. 221). Through such an experience they are able to feel into, envision, and embody the moral imperative of the archetypes for their time (1934, pp. 3-41). The capacity of the individual to transform themselves and the failures of their time is echoed by Erikson (1958), who studied the way people respond differently to the sociopolitical distress of their time. He stated:

Some young individuals will succumb to [a] crisis in all manner of neurotic, psychotic, or delinquent behavior; others will resolve it through participation in ideological movements passionately concerned with religion or politics, nature or art. Still others, although suffering and deviating dangerously through what appears to be a prolonged adolescence, eventually come to contribute an original bit to an emerging style of life: the very danger which they have sensed has forced them to mobilize capacities to see and say, to dream and plan, to 
design and construct, in new ways . . . [and] . . . create something potentially new: a new person; and with this new person a new generation, and with that, a new era (pp. 14-15, 20; emphases added).

Erikson's thoughtfulness is also captured poetically by Joyce (1916) who ends his book Portrait of the artist as a young man with his main character Stephen Daedalus proclaiming, "within the smithy of my soul I create the uncreated future of my race" (p. 237). For such sensitive individuals, facing the ills of their time and crafting a responsive identity often requires some retreat from societal roles and community. While such a retreat follows a rich historical precedent, Jung does not talk about it as one phase of a psychoculturally developmental process. Instead, following 19th-century thought that privileged Western, white, male consciousness, he privileges the individual phase of psychocultural development while deprecating the role of the group. While he did attend to how instinctive energies arise in groups, he did not focus on the conscious group. Instead, he asserted that "the total psyche emerging from the group is below the level of the individual psyche. ... The psychology of a large crowd inevitably sinks to the level of mob psychology" (1950, p. 125). Jung's critical attitude toward groups explains why he had difficulty articulating the theoretical basis for his visions of a collective self-aware human consciousness. Frankly speaking, despite his interest in a self-aware collective, he does not pursue working out the group practices needed to see if a self-aware group consciousness is possible. Without such theory and practice Jung retreats into psychotherapeutic practices that privilege the individual. ${ }^{3}$

While many of Jung's followers are part of the 20th-century project to articulate the theory and develop the practices that support some form of "healing" from something identified as "individual psychopathology," and while his approach to psychotherapy has also supported our understanding of "individual development," there is still a significant divide in Western culture between the relatively esoteric treatment of individuals and a more robust focus on the psychocultural ills of our time. Simply put, it is not enough to trace our suffering to our family histories; our families are, themselves, embedded in a larger psychocultural reality with its own driving and restraining forces. Thus, our use of psychology, to date, does not nearly address its full potential as identified by firstgeneration psychological thinkers such as James (1890/1950), Dewey (1929), Erikson (1958), and Jung (1931). In fact, Jungian historian Shamdasani (2003) offers the following critique of the Jungian community's efforts to attend to Jung's vision of psychology: "The history of Jungian psychology has in part consisted in a radical and unacknowledged diminution of Jung's goal” (p.15). 


\section{How are we to interpret and do something about the loss of Jung's vision?}

First, Jungians could leave the Commons and politics to others and continue our esoteric pursuits. Our contribution to clinical psychology continues to be substantial, and there is a growing awareness that Jungian thought makes a significant contribution to the arts and humanities. However, there is a recognition that we are rushing towards the edge of some collective unknown that may interrupt our preoccupation with the fractal patterns of individuation that can too easily move us away from one another. Climate change will likely, eventually, cut through our class protections. The growing global refugee crisis and the repugnant rise of nationalism also threaten our privilege. Alternatively, we could recognize that Jung was a man of his time who could not fully appreciate the larger psychocultural forces at work in the 19th and 20th centuries. In particular, Jung had no support to recognize the way in which the splits in the social sciences were symptomatic of psyche's fractures along "public" and "private" fault lines (Bellah, Madsen, Sullivan, Swindler, Tipton, 1985, pp. 43-46; Tronto, 1993; Samuels, 1993, p. 55; Sandel, 1996, p. 18; Dunlap, 2008, pp. 196-199). In other writing I identified the public/private divide as a "cultural complex," drawing from the work of Singer (2004) and Kimbles (2004) (Dunlap, 2016, pp. 86-87). While Jung was creative at the edges of these splits, he made little effort to work out a means of forming the larger, collective being he imagined and did pursue theoretically (Jung, 1939, pp. 275-283; 1946b, pp. 177-178).

Having acknowledged both Jung's interest in cultivating group consciousness and his bias against it, post-Jungians can pursue his unitive vision without perpetuating his prejudices and those of his subgroup. Researchers can think of the divide in our interest between society and the individual as representing a divergence in inquiry that is currently playing itself out. If we are moving toward a convergence in thinking, psychological scholars would likely see a wide range of research emerging from numerous social sciences that implies, invites, or directly states that we need to inquire about a fuller spectrum of our psychocultural and political experience. Researchers can look for overlap by asking questions about the shared interests of seemingly disparate disciplines. Here is one such orienting question I ask: "Is there a common, multidisciplinary interest in articulating the theory and cultivating the practices that would enable us to draw from both the wisdom of Jung's understanding of the individuation process and the need to learn how to form large-group identities that are not politically reactive but, rather, actually activate our 'political development"' (Pye, 1966; Samuels, 1993; Dunlap, 2008; Fukuyama, 2011)?

Volkan (2006) followed Erikson's (1958) idea of individual identity when he 
defined large-group identities ranging from thousands to millions as "a permanent sense of sameness, sharing certain emotional and ideational sentiments [around] ... historical, political, and psychological factors" (pp. 98-99). Such groups define themselves in relation to

... ethnic, religious, national, or ideological bases which . . . when under stress [can turn to] violence in order to erase the threats, whether real or fantasized, to their sense of "we-ness." Or, they would simply be murderous in order to maintain an illusion of superiority over those who they openly or secretly felt to be inferior or less human. (pp. 199-206).

Is there a convergence across at least the social sciences, if not more broadly, that would enable us to respond to the way large-group identities form or the way they become violent? I will pursue this question drawing from Jung's (1931) optimistic image of the species in harmonic coordination, Erikson's (1958) assertion that individual transformation leads to the mobilization of capacities that support a new identity and thus a new era, and Jung's (1946a) understanding that such transformation leads to morally significant cultural leadership (p. 221).

Jung (1934) examined the lives of several mystics who made significant contributions to the moral leadership of their times, including Nicholas of Cusa, whose path of individuation transformed him from a farmer, soldier, and father into the mystic Brother Klaus. Klaus's transformative archetypal vision of the Trinity evoked painful religious feeling in him that transfigured his countenance, making him unbearable to look at (p. 3-41; cf. 1936, p. 201). Yet, over time, he became a cultural leader who was sought out by the political leaders of his time. These events suggest that the archetypal image had a profound emotional impact that, as Klaus integrated it, led him to a new form of emotional intelligence that was central to his "cultural leadership" (Omer, 2002). Emotional intelligence is "the capability of individuals to recognize their own, and other people's emotions, to discern between different feelings and label them appropriately, to use emotional information to guide thinking and behavior, and to manage and/or adjust emotions to adapt environments or achieve one's goal(s)" (Wikipedia).

Following this hypothesis, I suspect that effective individuation activates a depth of feeling associated with the religious experience that transforms the individual and through that individual's leadership the surrounding culture. In order to explore these propositions I will draw attention to an emerging cross-disciplinary language to account for the role of emotion in the activation of the capacities that, as Erikson (1958) noted, lead to a new individual identity, a new generation, and a new era.

Following this thread, there has been a significant increase in interest in the function of emotion in human experience across many social sciences. As I will delineate in the 
next sections, social scientists are increasingly interested in the psychocultural function of emotion. These include clinical psychologist Fosha (2000), cultural anthropologist Reddy (2001), historian Rosenwein (2006), English professor Gross (2006), cognitive scientist Lakoff (2008), political psychologist Westen (2008) and a range of affect scientists to be discussed below. Following the work of Omer (2002), president of Meridian University, I have come to understand that emotions are the rudiments of specific leadership capacities that contribute to the well-being of individuals and groups as well as to a community's ability to address the political and moral issues of a time. Certainly the notion of emotional intelligence has become quite popular. However, again, is that not primarily an individual phenomenon, or can we say that groups develop emotional intelligence?

\section{What to do with emotion, what to do with one another}

For the longest time poets, scientists, political leaders, and the rest of us have wondered what to do with our feelings. Such interest is longstanding and can be combined with recent research from a number of different disciplines to identify opportunities to work with emotion, to attend to it as part of the life of groups and communities for the sake of learning about and effectively engaging its role in the formation of large-group identities. It is useful to understand that in Western culture the study of emotions is longstanding. While it is beyond the scope of this paper to do justice to the history of our exploration of our emotional experience, human beings have explored emotion, passion, and sentiment since Aristotle and before. For my purposes, I will start this section with interest in the biology of emotion starting in the mid-20th century. At that time Princeton professor Tomkins (1962) founded an original approach to the study of emotion called affect theory (Nathanson, 1992, p. 28). Following Tomkins, Nathanson described the biological basis of our emotional experience in relation to the human "affect system" (p. 59). Like other systems within the human organism, the affect system and its related components function independently but in relation to other functional systems. Each of the primary "affects" is a response to a mammal's environment, such as sadness over loss, anger at being thwarted, fear of threat, etc. (Omer, 2002). The affects are fixed patterns of response to environmental situations and have identical features in the old and young and are universal to the species as well as other mammals. They are rooted in the biology of the limbic system and are in an evolutionarily functional relationship with many other brain structures and aspects of physiology (Panksepp, 1994, p. 21; Scherer, 1994, p. 172). 
Affect theory primarily studies the individual's experience of emotion. While this preference has led to significant if not astonishing results, it may also perpetuate a modern bias toward psychologizing emotions, that is, defining emotions in relationship to the biology and psychology of the individual. Gross (2006) is curious about this psychologizing of emotion. He asserts that prior to the 18th century emotions served primarily a social and political function. Gross notes Descartes's dismissal of prior social and political writings on the passions and his understanding that emotions are simply available to individuals in their own experience. Gross cites Descartes, "every one has experience of the passions within himself[;] there is no necessity to borrow one's observations from elsewhere in order to discover their nature" (p. 22). While such exploration of the individual's experience of emotion has led to the "democratization of emotion" Gross thinks that this project is at best incomplete and at worst a distraction, coming at the expense of our being able to reflect upon the social function of emotion (p. 50).

In his efforts to reconstitute "social emotions," Gross identified the way in which emotions were intertwined with social institutions such as "slavery and poverty," which were utilized as part of asymmetrical power dynamics, enabling access to and use of emotion for some and not others (pp. 4-5). Here, passions assume a "public stage rather than private feelings" (p. 2 emphasis in the original). Sociologist Franks echoes Gross when he wrote that emotions are an "inseparable part of the social process" (qtd. in Rosenwein, 2006, p. 1).

Working with this idea of social emotions, Loyola historian Rosenwein (2006) identified the way in which groups of people form "emotional communities" within which "people adhere to the same norms of emotional expression and value-or devalue - the same or related emotions" (p. 2). Rosenwein tapped into the 1985 work of Stearns and Stearns, who use the term "emotionology" to describe "the standard that a society, or a definable group within a society, maintains toward basic emotions and their appropriate expression" (qtd. in Rosenwein, p. 7).

Drawing from her research into the political use of emotions in the Middle Ages, Rosenwein compared how the political power of one 7th-century papal court drew from the repression of emotion and the privileging of thinking only to be followed by another court whose power was linked to the way it "seethed with passion" later in that same century (p. 193). In these descriptions Rosenwein explored medium and large-group identities in relationship to the emotional communities they formed (pp. 199-200). Embedded in each were distinct values, attitudes, and identities that carried their own weight in relation to the political developments of that time. However, Rosenwein limited her assessment to the idea of development as simply change. While complex, her 
idea of change did not address the moral dimension that Jung identified as a defining feature of the transcendent function and, by implication, of cultural leadership (1946a, p. $221 ; 1958$, p. 68,82$)$. This lack of a normative statement is made clear in her book's conclusion:

By looking at emotional communities, we have seen not just that this or that emotion changed its meaning and valuation but more importantly that whole systems of emotion-integrally related to the traditions, values, needs, and goals of different groups - could come to the fore or fade away within a short span of time. (p. 203)

While significant in the development of our understanding of the social and political function of emotions, Rosenwein did not weigh in on the issue of the culture's or the species' moral development. She did not bring in any moral evaluation to her subject matter, which may be entirely appropriate for her discipline. However, Jung (1946a) believed that we must address moral questions, as he did not hesitate to do. He asserted that through the individuation process individuals integrate what has been repressed by their society and thus gain moral clarity, which enables them to become the moral leaders of their time (p. 221). Is there a connection between the social function of emotion as described by Rosenwein and the moral capacity of Jung's individual? If so, is there a way to connect the idea of emotional community to the moral development of largegroups? In order to formulate an answer, I will turn to the work of clinical psychologist Fosha (2000) to explore the role of emotion in individual development.

According to Fosha, lasting change in psychotherapy requires establishing a trusting relationship between client and clinician in order to explore repressed emotional experience. Through the therapeutic relationship the client experiences a remedy to "the alienation from and fraying of family and social life," which leads to fear of one's own emotional experience (2000, p. 13). Through psychotherapy fear of affect is eased as the therapist is able to show the client how to feel emotions, thus reconnecting the client to "core affect," namely, the emotional response we are capable of when emotions are not repressed (p. 15). Fosha asserted that such encounters are healing because they increase the experience of "aliveness and meaning" as "affective competence" (p. 21, 61).

Can the transformative power of affect work in large groups to change their identities to ones capable of managing the complexity of our time, activating the moral demand of the transcendent function, and acting with an increasing level of moral integrity? Would such transformation be a nascent counterbalance to the contagion of group emotion? The work of Duke university professor Reddy suggested that interest in the development of affective competence has historic precedent. 


\section{The French revolution and group identity formation}

Reddy (2001) described the way in which new attitudes toward emotions coemerged with Enlightenment political philosophy during the 18th century. The new emotional attitude was in response to an ascendant emotional community that challenged the political power of both the church and the monarch. Previously the French aristocracy and the larger social order were controlled by the monarch through extremely narrow social protocols imposed on the French court by Louis XIV. The restrictive "emotional regime" was used to pacify and control the aristocracy (pp. 124-126). It restricted the type of contact people could have with one another as well as how they could display feelings for different groups, limiting any displays of empathy for the suffering of the lower classes.

This notion of "rules" of emotional expression parallels what affect scientist Nathanson (1992) identified as the ability of groups to repress the experience of affect. Nathanson wrote, "A people may be raised in a culture or an environment that denies the existence of certain feelings; and even when an affect is triggered they may not feel it because the ability to perceive it has been extinguished" (p. 50). Nathanson extended something like the psychological idea of repression to groups in his idea that the culture trains individuals to ignore certain biological responses of their bodies, which limits their capacity to be able to identify the way that they feel. Such group-level repressions are clearly analogous to what Fosha (2000) said psychotherapy addresses as the individual's loss of connection to core affect.

Reddy and Nathanson parallel Jung's own thinking about groups, such as when Jung (1919) wrote,

Social, political, and religious conditions affect the collective unconscious in the sense that all those factors which are suppressed by the prevailing views or attitudes in the life of a society gradually accumulate in the collective unconscious and activate its contents. Certain individuals gifted with particularly strong intuition then become aware of the changes going on in it and translate these changes into communicable ideas. (p. 314).

Here Jung identified the antidote as "communicable ideas" arising from gifted individuals. If we add the role of affect along with the cultivation of a public emotional intelligence, we can point Jungian "thought" toward these more recent social science considerations of the role of affect in transformation. In my earlier (2008) work on "affect freedom," I defined a public emotional intelligence as "the capacity to draw from a full range of the biological and psychocultural functioning of our emotional experience 
for the purpose of: assessing our own and our community's needs; motivating and directing ourselves to learn and engage in our communities; and, connecting to one another convivially, or in conflict for the sake of resolution, as we move toward shared projects and action in the world (pp. 14-16).

The rise of the 18th century French regime led to 1) significant emotional needs that "gifted individuals" intuited and 2) new ways of gathering where people could find what Reddy called "emotional refuge" with one another, which he defined as an "organization ... that provides safe release from prevailing emotional norms and allows relaxation from emotional effort" (2001, p. 129). For example, Reddy identified the Parisian salons as a location where the liberal intellectual elite could discuss new ideas about science and political philosophy as well as share new feelings, often between men and women, as an expression of the egalitarian values of the new political philosophy of laissez-faire liberalism. Similarly, men of different classes gathered together in the Masonic lodges in the name of brotherhood, breaking the emotional restrictions that had divided the classes (p. 145). Here, it is noteworthy to compare the warmth of brotherhood within an ascendant emotional community with the warmth of the emotional community established in psychotherapy. Both expand the emotional range of participants, offering them an experience of significant freedom, which certainly has been at work during times of cultural renewal, such as the 1960s, however problematic and incomplete that time was.

Also of importance is the idea that the French Enlightenment not only extended Locke's laissez-faire liberalism and its political implications but also began a very overt articulation of a positive role in our public life for emotion (Dewey, 1929, p. 4). While emotion has gone in and out of style as a contributor toward social and political transformation, the French Enlightenment may mark a time when such valuation was explored uniquely, as a direct focus of consciousness, which did not work out well at all.

Prior to the French Revolution the exploration of emotional refuge became willful, overt, and quite conscious. Reddy (2001) wrote, "For a few decades, emotions were deemed to be as important as reasoning in the foundation of states and the conduct of politics" (p. 143). Passion was celebrated as "the font of morality" (Rosenwein, 2006, p.198). Unfortunately, the emotional refuge of the French Revolution did not lead to the broader adoption of a new emotional community. Reddy traced how an indulgence in emotion as "sentimentality" actually contributed to the "reign of terror" that engulfed France in 1793, which led to "the end of almost all attempts to establish a positive role for emotions in politics" (p. 142). In the historical context of this time the exploration of the previously undifferentiated, shadowy feeling function could not be easily integrated into consciousness, which led to a mass-mindedness Jung (1959) understood as 
emotional contagion (p. 9; cf. 1946a pp. 218-226). Not only were the ideas of the French Revolution met with violent resistance, but the emotional freedoms explored did not translate readily into Fosha's idea of affective competence. In fact, the emotional refuge of sentimentality prior to the French Revolution gave way to a new emotional regime that led to the "reign of terror" and to the deaths of thousands.

In combination, emotional regimes and refuge may be part of a developmental process within Western culture through which the culture may grow in complexity and moral capacity, but this outcome is not certain. Such events may also lead to the worst horrors that consolidate "transgenerational trauma" (Volkan, 2006, p. 124). However, Reddy (2001) did not directly weigh in on the moral implications of such events. Like Rosenwein (2006) and others, he did not bring a moral axis into the equation. Instead he simply stated that there are times when cultural elites turn toward or away from emotions as a source of social and political knowing. Where are we today in that rhythmic interplay between thinking and feeling? Is turning back and forth capricious, or is there a moral dimension - a telos— to this interplay?

\section{Is there a process of psychocultural development taking place in relationship to our psychological functions?}

According to Rosenwein and Reddy, one group may privilege thinking while another may privilege feeling, and these choices are significant to the politics of a time. Under consideration here is the idea that during times of cultural transformation different psychocultural functions (thinking/feeling, sensing/intuiting) emerge to support a developmental process. For example, in the early to mid-17th century, Descartes championed the function of thinking, claiming that the individual could create culturally valid knowledge through the differentiation of "clear and distinct ideas" (Dunlap, 2008, pp. 168-170). Similarly, a generation later, Locke argued that our sensory experience was also a source of culturally valid knowledge. These assertions were not politically neutral; they challenged the traditional order by turning attention to the individual's autonomy and creative abilities and away from the emotional relations that maintained embedded and oppressive collectivity. This new attitude toward the individual's autonomy became part of the rise of Enlightenment thought and the politics of laissezfaire liberalism (Dewey, 1929, p. 42).

With the rise of sensing and thinking as sources of cultural knowing, what was the position of emotion? Significant efforts were made to find a public place for feeling in politics. During this early modern time Hobbes, Hume, and Smith all sought to find a role for emotion in politics (Gross, 2006, pp. 5-6, 44). For example, prior to his 1776 
Wealth of nations, Smith explored emotion in his 1759 book The theory of moral sentiment as a source of social glue, thinking that we would naturally be able to use it to imagine into the suffering of others and thus develop a natural "sympathy" for that suffering that would guide our moral considerations. Smith (1759/1976) wrote that the reality "that we often derive sorrow from the sorrows of others, is a matter of fact too obvious to require any instances to prove it" (Smith, 1976, p. 47).

Smith's work was part of a broad valuation of the social function of emotion that I described earlier. However, as I also noted, this attention to feeling, as sentiment, did not work out well. Instead of continuing the experiment with sentimentality and its implications for an emerging public emotional intelligence, Western culture by and large retreated into an overvaluation of rational thought and an abandonment of the public use of emotion as typified in the words of Utilitarian thinker Mill (1873/1989). While Mill later had a change of heart, he described Utilitarians as "ashamed of the sign of feeling. For passionate emotions of all sorts ... we did not expect the regeneration of mankind from any direct action on those sentiments, but from the effect of educated intellect, enlightening the selfish feelings" (Mill, 1873/1989, p. 98).

While the French experiment with emotion as sentimentality failed, the subsequent recoil against emotion is part of a cultural retreat from the promise of the Enlightenment. Unfortunately, Descartes's and Locke's revolutionary individual became, 150 years later, a barren individualism, stripped of public feeling or what Beebe (2017) considered "extraverted feeling" that involves "mutual trust and the harmonious working of groups" (p. 102). This modern individualism was recognized and described as early as 1835 by French sociologist de Tocqueville (1835/1945) in his critique of the new American culture when he said,

Individualism is a mature and calm feeling, which disposes each member of the community to sever himself from the masses of his fellows and to draw apart with his family and his friends, so that after he has thus formed a little circle of his own, he willingly leaves society at large to itself. (p. 98)

While the differentiation of thinking and sensation is part of the revolution that led to the Western modern identity, the neglect of emotion in the public sphere led to its being relegated to our private lives, which are problematically associated with women and children. I suspect that the abandonment of emotion exacerbates the public-private divide in our culture, which has been associated with a level of political apathy dangerous to our times (Tronto, 1993; Samuels, 1993, p. 55; Sandel, 1996, p. 331; Dunlap, 2008, p. 198). 
The disparagement of emotion continues to this day particularly in liberal political communities where policy analysis and rational debate are supposed to lead to civic clarity (Dunlap, 2008, p. 52). However, as Lakoff (2006) noted, "rationalism is the bane of liberalism" (Sonoma California, public speaking; cf. 2008, pp. 1-15). Lakoff and Emory professor Westen are only two of the current thinkers trying to educate political liberals about the potency of emotional experience; this education is on-going. Most recently, after the 2016 presidential election, Mother Jones writer Hochschchild wrote about the need to attend the emotion-based "deep story" of those who voted for Donald Trump, and Slate writer Jess Zimmerman exaggerated this point in order to drive it home by arguing that the political left needs to stop focusing on facts and instead focus on feeling. In my own research with progressive and liberal political leaders, I, too, find an overly rational identity that restricts the left's ability to form cohesive, self-renewing groups. I wrote in detail about this group-level identity crisis/dilemma in my 2008 book Awakening our faith in the future: The advent of psychological liberalism.

In light of recent research into the sociopolitical function of emotion, Jung's exploration of the moral potency unleashed through the transcendent function by an encounter with an archetypal image may be thought of as only the first step in a fully transformative experience requiring our addition of an emotional element, which Fosha (2000) brought to our attention. Based on my research, I tentatively traced a developmental line from archetypal image to emotion, to a communicable idea, and then to new and more morally developed social and political practices and relations, which I characterize as the movement from "image" to "institution" (Dunlap, 2008, pp. 99-113). Based on this developmental trajectory, I suspect that it is possible to learn to develop a public emotional intelligence, supported by the differentiation of extraverted feeling that would enable us to weave group cohesion as a nascent prerequisite to the emerging exalted group mind envisioned by Jung. Exploring Omer's work will deepen our reflections on the role of emotion in cultural transformation.

\section{The transformation of affect into capacity}

Omer (2002) was interested in the practices groups cultivate around affect and emotion that support collective identity transformation. Paralleling what Fosha (2000) wrote about a therapist's need to show clients how to feel, Omer linked affect transformation to cultural leadership to suggest that cultural leaders actually need to show a group or a people how to feel, that is, how to transform affect and emotion into a morally disciplined feeling function. I draw the following description of Omer's thinking from an earlier paper of mine. 
The following historical events exemplify Omer's insight: during the salt march from Sabarmati to Dandi Mahatma Gandhi exposed himself to physical violence and incarceration in order to draw the attention of the world to the British repression of shame for their treatment of his people (Omer, 2002). Gandhi's acts of cultural leadership transmuted his own and his follower's fear into courage and the British people's shame into a rudimentary conscience, one capable of recognizing the social trauma of prejudice and their own active and passive perpetuation of this horror. Martin Luther King's own path followed Gandhi's as he helped the American people face their shame for the treatment of African Americans. King recognized the role of affect in leadership development when he extoled his followers "if he puts you in jail, you go into that jail and transform it from a dungeon of shame to a haven of freedom and dignity." (Dunlap, 2014, pp. 141-151).

In this description we may be seeing one of the primary mechanisms for the reciprocity between individual development and cultural transformation. Omer introduced the moral axis into the relationship between individual and collective development that was skipped by Reddy (2001), Rosenwein (2006), and others. What do we know about group development that could support Omer's thought?

\section{Agazarian's theory of living human systems}

Agazarian has developed a "theory of living human systems" (TLHS) (Agazarian, 1997). Her research draws from psychoanalysis, group theory, Lewin's (1951) theory of systems, attachment theory, and its recent connection to neurobiology. Agazarian founded Systems-Centered Training and Research Institute (SCT) to investigate how individual and group systems develop. She received the Presidential Award from the American Psychological Association in 2014 for her research.

SCT, a theory-driven approach to individual and group development, has been tested in thousands of group settings over several decades, giving rise to an international organization that assists a wide range of professionals and citizens interested in supporting human development simultaneously for individuals, organizations, and communities. SCT has become foundational for the work of psychotherapists treating individuals and groups. It also supports the work of human resource managers, organizational development consultants, clergy, educators, and community leaders.

The TLHS defines a hierarchy of isomorphic systems that survive, develop, and transform from simple to complex by discriminating and integrating differences. Each system exists in the environment of the system above it and is the environment of the system below it. The TLHS maintains that groups are energy-organizing, goal-directed, 
and self-correcting. All systems are similar in structure and function and differ depending on context. This claim is derived from the recognition that a psychology of the individual is not sufficient to account for the behavior of groups. As group theorists de Mare, Piper, and Thompson (1991) wrote,

The problem for the individual is the intrusion into the individual situation of the repressed unconscious. For the large-group, on the other hand, it is consciousness that is in jeopardy, both for the individual and for the group's equivalent of consciousness, namely communication and organization. The problem for the rudimentary large-group is its mindlessness; not how to feel, but how to think (pp. 408-11).

Here SCT matches up with Jung's concern about the mass-mind. Both recognize the risk of the individual's being submerged in loss of consciousness that can take place in groups. As Agazarian stated, "we are all puppets on the strings of group dynamics" (2013, Philadelphia SCT annual conference). Like Jung, she recognized that we are always susceptible to being submerged in collective affect, which invites our diligence and humility. When groups are trained in attending to group dynamics, contagious affect is transformed into the feeling function needed for a public emotional intelligence, which supports the dialogue needed to keep a group thinking.

SCT methods are used around the world to impact positively small and large groups, to support their learning how to attend to the risks of the mass-mind. Agazarian's TLHS is comprehensive in that it presents a developmental template that maps human experience in a way that allows intervention and understanding to be accessible and effective at all levels of systems functioning.

From an SCT perspective, the transformation of large-group identities becomes possible with the support of SCT leadership because they are able to work directly with group "shadow dynamics" that are identified as "restraining forces" to group development. Specific restraining forces that are brought to consciousness in an SCT group include scapegoating, defensive posturing, excluding new members, stereotypical conflict, and intolerance. Following a "sequence of defense modification," social defenses were addressed first followed by anxiety, tension, depression, outrage, and survival roles (Agazarian, 1997, pp. 119-254). These defenses are recognized as restraining forces at individual, subgroup, and group as a whole levels. Also, being multigenerational, they are often a result of what Volkan (2006) recognized as transgenerational trauma (p. 124).

As groups move through the sequence of defense modification, the individuals reclaim difficult feelings previously projected onto others, as identified by Jung (1946a). As individuals embody a fuller range of "core affect" they withdraw shadow dynamics 
and contribute to an expanding emotional community, developments that support both immunity to contagious affect and the discourse needed to manage and integrate differences in thinking.

Agazarian (1997) followed other group theory that recognizes how groups progress from "flight" to "fight" during what she coined as the "authority" phase of development. As a group works through the various phases and stages, it is able to confront and contain the "crisis of hatred," a concept that reflects what plays out in many ways in almost every group that works together for any length of time. Successful resolution of this stage of development opens further stages that address issues of "intimacy" and "work" (Agazarian, 1997, pp. 37-38, 257-276).

\section{Functional subgrouping}

The TLHS implements a unique method of experiential group process called "functional subgrouping," a strategy used to engage differences and conflict in groups and thus to promote group development, that is, developing the complexity needed to discern and integrate differences. Functional subgroups are different from stereotypical subgroups that often split members and fixate them at a particular stage of development. In functional subgrouping, participants join around similarities first until they begin to discover "just noticeable differences" (Agazarian, 1997, p. 19). The system works in an environment of similarity and develops enough cohesion so that differences can come across the boundary without too much turbulence, and the system can use the difference as information to develop and transform. This focus on similarity is supported by recent research in neurobiology, particularly the idea of emotional attunement that echoes Fosha's (2000) idea of affective competence. Agazarian and Gantt have integrated the practice of functional subgrouping into a theory of the development of "group mind" (2010).

Functional subgrouping, along with other methods of facilitation, assists in the development of the capacity to explore and integrate differences both within the individual and within the membership of a group or organization. For example, while the SCT community is primarily made up of Caucasian members, there is a growing recognition of the need to attend to the issue of diversity, based on the moral principle of inclusivity. In one recent large-group meeting of over one hundred members, functional subgrouping was used to explore the lack of diversity in its membership. One member raised the issue of diversity, which evoked both support and frustration on the part of different group members. While the member risked being scapegoated, the practice of functional subgrouping helped shift the focus away from the individual and 
toward the opportunity to explore the group's lack of diversity as it unfolded within the community. Following this discipline, members were supported to build the subgroup concerned about diversity, which led to interest in doing outreach to communities of color for the next conference as well as designing a specific workshop on social justice. While a clear path toward cultivating diversity was not found, the community connected to and was directed by the embarrassment and frustration linked to an emerging public emotional intelligence.

While such group work does not automatically address the conflicts within and between large groups, functional subgrouping has been used effectively in increasingly larger groups of up to 150 and more to work with organizational conflict. Further, it offers a clear line of inquiry for future research linked to the development of leadership capacities related to group functioning.

In my own political practice I have been using functional subgrouping to support political and other community leaders to develop a public emotional intelligence, which they report has made them significantly more effective in their leadership. Members in my group are becoming skilled at recognizing and undoing their own and other people's defenses, which is giving them more confidence in helping the groups they participate in develop, that is, become more complex, self-correcting, and inclusive. Participants report greater sensitivity to group dynamics in their organizations, which is helping them recognize, not take personally, and be attentive to the suffering of others. Attending to these dynamics supports better connection with other people, sensitivity to the positive role of difference in group development, as well as a group's task-oriented agendas. I offer a more detailed account of this "hope and leadership" group in other writing (Dunlap, 2017). Also, over the last four years I have been bringing emotion-focused group practices, including functional subgrouping, to multiple Jungian communities at conferences in Chicago, Los Angeles, New Haven, Rome, and San Francisco. With few exceptions, these experimental groups have brought positive feedback, including comments about how Jungians simply need such group work and should start all conferences with such a conscious approach to focusing on the life of the group. Again, I do not assume that the bare-bones theory presented here or even the large-group practices described will easily translate into theory and practices that will help us transform our large-group identities. However, theorizing about and practicing with large groups is an appropriate step in that direction. As described by de Mare (1991),

the large group reflects our sociocultural environment in a way that the small group cannot possibly do, pointing out that the group is not meant to provide psychotherapy for the individual so much as to contribute towards the process of humanizing society. Large groups ... . should 
take up the challenge and set about creating a climate in which they can form an established part of our culture (pp. 433-435).

To humanize society will require some empirical evidence that groups develop, that is, that they can better discern and integrate differences, which becomes the basis for the theory and practice of psychocultural development described here. It is possible to recognize those among us who have developed and live up to a new moral vision of humanity based in inclusivity. It is also possible and necessary to build groups that complete the collective phase of psychocultural development implied by the moral vision of cultural leaders, thus broadly embodying the new consciousness. Clearly there are moral opportunities involved in large-group research.

\section{Conclusion}

Jung was of two minds about groups. He saw them as a primary source of destructive unconsciousness, speculating that they can only become "mobs" (1950, p. 125). Yet he also imagined that the species could become self-aware and have god-like powers to be used to help humanity (1931, pp. 349-350). Acknowledging this tension in Jung prepares the ground to develop the theory and practices of a distinctive Jungian political psychology. Such development can combine his sense of the moral imperative of individuation with what we are learning from multiple social sciences about the psychocultural function of emotions and group development.

Cultivating the approach traced here, a new type of "psychocultural practitioner" could experiment by engaging existing social-change groups for the sake of increasing their effectiveness. When it is applied to political organizing, what we think of as the leadership of the "political left" could become more capable of embodying the public emotional intelligence that would help them to cultivate greater awareness within their organizations of the difference between stereotypical group behavior that restricts a group's development at a specific stage and proper movement through the stages of development. With greater coordination, the left would be able to activate the political energy needed to turn enough of the electorate's attention to issues of social justice and environmental sustainability. In order to activate this political energy it will be necessary to engage the public's emotional intelligence, particularly its extraverted feeling, which would enable a range of political groups to develop commonality between themselves rather than being caught up in their differences. This goal reclaims the vision of psychology articulated by first-generation psychological thinkers, because it supports the use of a psychological attitude to activate greater group cohesion, supporting groups 
generally to recognize the universality of human experience and begin shifting away from their narrow group identifications.

While I suspect that such efforts to bring a psychological attitude to the politics of community, nation, and world are already taking place, I also think that these efforts are taking place without sufficient help from psychology. What might be done about this inadequacy?

Currently, the Jungian communities have been curious about our possible impact on politics. While many invaluable efforts have gone into talking among ourselves, including holding conferences, writing and publishing papers, and holding online forums, we have not quite known how to take our work public. We need to take the time to identify a constituency or referral base for a new psychological vocation. By thinking about the work we could do, we would be recognizing that our own theorizing about politics is of limited use, particularly when we are not being read by those engaged in politics. By imagining a service that others would value, we place ourselves in the position of being psychocultural practitioners; that is, we set out to help existing organizations work out the limitations of their own identities. As we learn how to be such practitioners we would likely attract considerable attention, which will help us grow our own communities. Essential to learning how to be psychocultural practitioners will be our attending to the limitations of our own large-group identities, thus becoming the change we wish to see in the world. By attending to our own organizations, we will be able to learn more about their limitations while cultivating the fertile ground within which to train the new generation of psychocultural practitioners needed by our time.

\section{Works Cited}

Agazarian, Y. M. (1997). Systems-centered therapy for groups. New York, NY: Guilford. Reprint (2004). London, UK: Karnac.

Agazarian, Y. M., Gantt, S. (2010). Developing the group mind through functional subgrouping: Linking systems-centered training (SCT) and interpersonal neurobiology. International Journal of Group Psychotherapy, 60 (4) 515-544.

Beebe, J. (2017). Energies and patterns in psychological type. London, UK: Routledge Press.

Bellah, R., Madsen, R., Sullivan, W., Swindler, A., Tipton, S. (1985). Habits of the heart, Berkeley: University of California Press.

Coleman, A. (1995). Up from scapegoating: Awakening consciousness in groups. Wilmette, IL: Chiron.

Dewey, J. (1929). Liberalism and social action. New York, NY: Capricorn Books.

Dunlap, P. (2008). Awakening our faith in the future: The advent of psychological liberalism. London, 
Vol. 12, No. 1, 2017

\author{
UK: Routledge Press.
}

Dunlap, P. (2014). Jung's relationship to science and his concept of psychocultural development. In Jung and the question of science. edited by Ryan Jones. London, UK: Routledge Press.

Dunlap, P. (2016). Renewing our faith in groups: A moral imperative for our community. International Journal of Jungian Studies. Vol. 8 Issue 2. 85-97.

Dunlap, P. (2017). Integrating, not indulging in, difference: On our way to establishing unique political practices. The analyst in the polis. Book chapter from International Association of Analytical Psychology (IAAP) 2015 Rome conference on Jung and Politics.

Erikson, E. (1958). Young man Luther. New York, NY: W.W. Norton.

Fosha, D. (2000). The transforming power of affect. New York, NY: Basic Books.

Fukuyama, F. (2011). The origins of political order. New York, NY: Farrar, Straus and Giroux.

Gross, D. (2006). The secret history of emotion. Chicago: University of Chicago Press.

Henderson, J. (1984). Cultural attitudes in psychological perspective. Toronto, Canada: Inner City Books.

Hochschild, A. (2016). “I Spent 5 Years With Some of Trump's Biggest Fans.” Mother Jones Magazine. Sept/Oct . http://www.motherjones.com/politics/2016/08/trump-white-blue-collar-supporters.

James, W. (1890/1950). The principles of psychology. New York: Dover Publications.

James, W. (1902) The varieties of religious experience. New York: Longmans, Green, and Co.

Jay, M. (1973). The Dialectical Imagination, Boston: Little, Brown, and Company.

Joyce, J. (1916) Portrait of the artist as a young man. New York: Colonial press.

Jung. C. G. (1919). The psychological foundations of beliefs in spirits. In Collected Works vol. 8. London: Routledge and Kegan.

Jung. C. G. (1931). Basic postulates of analytical psychology. In Collected Works vol. 8. London: Routledge and Kegan.

Jung. C. G. (1934). Archetypes of the collective unconscious. In Collected Works vol. 9.i. London: Routledge and Kegan.

Jung. C. G. (1936). Concerning the archetypes, with special reference to the anima concept. In Collected Works vol. 9.i. London: Routledge and Kegan.

Jung. C. G. (1939). Conscious, unconscious, and individuation. In Collected Works vol. 9.i. London: Routledge and Kegan.

Jung. C. G. (1946a). The fight with the shadow. In Collected Works vol. 10. Princeton: University of Princeton Press.

Jung. C. G. (1946b). On the nature of the psyche. In Collected Works vol. 8. London: Routledge and Kegan.

Jung. C. G. (1950). Concerning rebirth. In Collected Works vol. 9.i. London: Routledge and Kegan.

Jung. C. G. (1958). The transcendent function. In Collected Works vol. 8. London: Routledge and Kegan.

Jung. C. G. (1959). The shadow. In Collected Works vol. 9.ii. London: Routledge and Kegan.

Jung. C. G.. (2009). The red book. Ed. Shamdasani, S. New York: W. W. Norton. 
Journal of Jungian Scholarly Studies

Vol. 12, No. 1, 2017

Kimbles, S. (2004) A cultural complex operating in the overlap of clinical and cultural space. in S.

Kimbles and T. Singer (ed.) The cultural complex. New York: Brunner-Routledge.

Lakoff, G. (2008). The political mind. New York: Penguin.

Lewin, K. (1951). Field theory in social science. New York: Harper and Row.

de Mare, p., Piper, R., and Thompson, S., (1991). Koinonia: From hate through dialogue to culture in the larger group. Kindle version 5. London: Karnac.

Mill, J.S., (1873/1989). Autobiography. London: Penguin Classics.

Nathanson, D. (1992). Shame and pride: affect, sex, and the birth of the self. New York: Norton.

Omer, A. (2002). A glossary of imaginal transformation practice (ITP). Meridian University: Petaluma, California.

Panksepp, J. (1994). The basics of basic emotions. In P. Ekman \& R. Davidson (eds) The nature of emotion, New York: Oxford University Press.

Pye, L. (1966). Aspects of political development. Boston/Toronto: Little, Brown \& Co.

Reddy, W. (2001). The navigation of feeling. Cambridge: Cambridge University Press.

Rifkin, J. (2011). The empathetic civilization.

Rosenwein, B. (2006). Emotional communities in the early middle ages. Ithaca: Cornell University Press.

Samuels, A. (1993). The political psyche. London: Routledge.

Sandel, M. (1996). Democracy's Discontent, Cambridge: Harvard University Press.

Scherer, K. (1994). Evidence for both universality and cultural specificity of emotion elicitation. In P. Ekman \& R. Davidson (eds) The nature of emotion, New York: Oxford University Press.

Shamdasani, S. (2003). Jung and the making of modern psychology: The dream of a science. Kindle version 5. Cambridge: Cambridge University Press.

Singer, T. (2004). The cultural complex and the archetypal defenses of the group spirit. The cultural complex. Ed. Kimbles, S. and Singer, T. New York: Brunner-Routledge.

Smith, A., (1759). The theory of moral sentiment. Indianapolis: liberty Classics.

Smith, A., (1776). A wealth of nations. London: W. Strahan and T. Cadell.

de Tocqueville, A. D. (1835/1945). Democracy in America, vol. 2, New York: Alfred Knopf.

Tomkins, S. (1962). Affect Imagery Consciousness: Volume I, The Positive Affects. London: Tavistock.

Tronto, J. (1993). Moral Boundaries: A Political Argument for an Ethic of Care, New York: Routledge.

Zimmerman, J. (2017). "Its time to give up facts.” Slate. http://www.slate.com/articles/health_and_science/science/2017/02/counter_lies_with_emotions not_facts.html

Volkan, V., (2006). Killing in the name of identity: A study of bloody conflicts. Kindle version 5. Charlottesville, Virginia: Pitchstone.

Westen, D. (2008). The political brain. New York: Public Affairs.

Wikipedia. https://en.wikipedia.org/wiki/Emotional_intelligence 
Vol. 12, No. 1, 2017

\section{Notes}

${ }^{1}$ In this and other writing I use the term "psychocultural" to refer to the interaction between the individual and cultural domains of human experience. While the term "psychosocial" might suffice, I think of culture as a broader category that references the way individuals, groups, and whole peoples form identities and the way these are relevant in psychological, political, and social studies interested in working with conflict. Also, Jung brings a unique perspective to this conversation in his attribution of a psychological/religious/moral dimension to the interaction between these domains of experience that is essentially developmental. In other writing I introduce the idea of Jung's theory of our "psychocultural development," which will be addressed in this paper as well (Dunlap, 2014).

${ }^{2}$ I recognize that the idea of the human capacity to be religious or to have religious experience may trouble some readers of this paper. I am following Jung, William James and many others who separate such an experience from its institutionalization in religious organizations. In my effort to explore the way we form our large group identities I recognized the need to challenge any idea or institutional form that abuses people or rationalizes that abuse.

${ }^{3}$ An interesting comparison can be made with the history of the Frankfurt School of Social Research. That school suffered many internal ruptures including the division between Eric Fromm and other faculty. While Fromm thought that broader social transformation would take place through the gradual impact of psychotherapy other faculty advocated revolution (Jay, 1973, p. 103). This split led to Fromm leaving the school, which continued to struggle to bring the psychological together with the political. 